\title{
A ESPECIFICIDADE LINGUÍSTICA E NÃO-LINGUÍSTICA EM ARTICULAÇÃO COM A ATIVIDADE DE LINGUAGEM
}

Albano Dalla Pria ${ }^{1}$

\section{RESUMO}

Apresentamos ao leitor uma reflexão sobre questões que nos são pertinentes há algum tempo sobre a atividade construtora de representações (atividade linguagem) e as representações construídas que configuram a diversidade de experiências (sujeitos) e de meios expressivos (sistemas semióticos). Dedicamos esforços para dialogar com outras identidades que optaram por caminhos outros na compreensão da especificidade linguística e não-linguística e na sua relação com a linguagem. Em nossa trajetória, articulamos essas especificidades com a atividade de linguagem como ponto de partida da nossa reflexão e a localizamos como a gênese da produção e do reconhecimento do material simbólico (empírico) que é a causa e o efeito do diálogo graças à função integradora de cada situação particular de diálogo e à função estruturante da noção e do domínio nocional. Ao final, oferecemos ao leitor um exercício que coloca em movimento a reflexão desenvolvida neste artigo.

Palavras-chave: Diálogo. Meios expressivos. Linguagem. Línguas naturais.

\section{INTRODUÇÃO}

Agradecemos à Revista Signo e aos demais colegas que publicaram neste volume pela oportunidade de lhes oferecer nossa trajetória de reflexão sobre o tema O texto e a multimodalidade textual. A relevância que esse tema tem assumido entre os linguistas é motivada pelos resultados dos avanços da tecnologia, tais como as redes sociais e uma vasta gama de aplicações a que se tem acesso pela internet. Com efeito, a linguística está cumprindo o papel de fornecer respostas padronizadas, fáceis de usar e eficientes a outros domínios dentro do projeto instrumental e utilitarista de ciência que uma sociedade assim tem organizado. A multimodalidade textual ou o texto multissemiótico (combinação de mais de um sistema semiótico na produção de significação) são temas recorrentes em domínios para os quais tanto as línguas quanto outras formas de expressão (a diversidade nas formas de expressão) são entendidas como instrumentos que os sujeitos utilizam para algum fim. Trata-se de um conceito que está colocado a serviço da máxima eficiência na comunicação entre sujeitos. Assim, um sujeito codifica um 
conteúdo que é transferido para outro sujeito que o decodifica tal como se espera que um autômato o faça.

Esse caráter instrumental da linguística é tributário dos conceitos de langue (código) e de ciência no qual certo tipo de linguística se desenvolveu. No conceito de langue (código) e de signo utilizados para pensar os arranjos léxico-gramaticais das línguas particulares assim como outras formas de expressão, tais como imagens, música, gestos e sons, está implícita a opção metodológica por abstrair da diversidade experiencial e diversidade das formas de expressão em detrimento dos conceitos de coesão e coerência e da estabilidade das estruturas cognitivas (média da experiência) dos sujeitos presente no conceito de signo. Os reducionismos decorrentes do conceito de ciência no qual essa linguística se desenvolveu a distanciaram do diálogo com a heterogeneidade constitutiva da linguagem, incluindo a diversidade das formas de expressão, e a encerraram na especificidade do domínio línguas e dos sistemas que as descreve. Podemos perguntar como passamos de um sistema a outro? Como esses sistemas dialogam entre si? Como esses sistemas chegam a ser o que são? Semelhantemente podemos perguntar como podemos passar de um meio expressivo a outro? Por exemplo, como podemos passar das línguas para as imagens e vice-versa? Como os meios expressivos dialogam entre si? Como os meios expressivos chegam a ser o que são?

Se continuarmos a pensar sobre os meios expressivos na sua singularidade, abstraindo da diversidade experiencial (média da experiência dos sujeitos) e da diversidade das formas de expressão e dos meios expressivos, não ultrapassaremos o caráter instrumental ao qual referimos no primeiro parágrafo.

A opção metodológica que fazemos aqui é por considerar a linguagem como constitutiva da natureza humana, tal como o fazia Benveniste em suas publicações. No homem, a linguagem atua como mecanismo de equilibração e de adaptação ao empírico (diversidade de experiências e de meios expressivos). Articular o particular (meios expressivos e diversidade de experiências) com o universal (processos generalizáveis de organização da matéria) será o resultado de opções feitas ao longo de um percurso teórico original com o qual estamos comprometidos em nossa atividade de ensino e de pesquisa.

Estamos nos propondo a pensar a diversidade de pontos de vista sobre o tema deste volume a partir de nossa experiência teórica com uma teoria específica, 
a Teoria das Operações Predicativas e Enunciativas, e oferecer algumas conclusões resultantes desse movimento entre nossa identidade teórica e outras identidades. Isso requer primeiramente que explicitemos algumas opções teóricas neste artigo, tais como a tese da indeterminação da linguagem, a definição de linguagem como "uma atividade de representação, referenciação e regulação acessível somente através de sequências textuais, isto é, através do agenciamento de marcadores que são traços de operações subjacentes" (CULIOLI, 1990, p. 14), de línguas como "sistemas simbólicos de representação de significado que apresentam variações no tempo, no espaço, de uma cultura a outra, entre falantes, e intrafalantes" (CULIOLI, 1990, p. 14) e de linguística como "a ciência cujo objetivo é compreender a atividade de linguagem através da diversidade das línguas naturais (e através da diversidade de textos, orais e escritos)" (CULIOLI, 1990, p. 14). Com efeito, o objetivo da linguística coincidirá com o objetivo da ciência, que é a apreensão de processos invariantes (formais) subjacentes à diversidade experiencial dos sujeitos e das formas de expressão.

O conceito de texto recobre tanto formas de expressão (arranjos léxicogramaticais) de línguas naturais quanto formas de expressão de outros meios expressivos. Em quaisquer casos, o que denominamos textos é resultado da atividade de linguagem sobre o empírico (diversidade de experiências dos sujeitos e de formas de expressão de meios expressivos). Para nós, o texto é um construto, não um dado, como o querem abordagens instrumentais da ciência. As formas de expressão estabilizadas em um texto são o resultando do esforço (trabalho) de um sujeito em fazer coincidir sua experiência particular com a diversidade de experiências, de formas de expressão e de meios expressivos com quais entra em contato. Segundo Cumpri (2009), parafraseando Culioli (1999):

\footnotetext{
O texto funciona não como transmissão de um conceito de um falante para seu interlocutor, mas como uma sequência de representações que resultam de um conjunto de operações realizadas por um sujeito enunciador que, em uma situação de enunciação (que inclui os interlocutores e um momento), busca construir um sentido. (CUMPRI, 2009, p. 28).
}

A atividade de linguagem é o que fundamenta todos os processos (caminhos) que a representação (configuração de formas de expressão particulares) a ser construída deve percorrer em sua constituição única e singular. 


\section{A ATIVIDADE DE LINGUAGEM}

A atividade de linguagem é o que possibilita ao sujeito tanto a produção quanto o reconhecimento de representações (formas de expressão) providas de significação, sejam arranjos léxico-gramaticais das línguas sejam arranjos de outros meios expressivos. Neste artigo, defendemos que essas representações são, ao mesmo tempo, produto da atividade de linguagem e caminho de acesso aos modos pelos quais essa atividade se realiza. Fazemos tal afirmação porque assumimos que as configurações delimitadas nas formas de expressão guardam vestígios das operações Ihes deram origem. Teoricamente manipulados, esses vestígios identificam operações que possibilitam teorizar os processos pelos quais os sujeitos produzem e reconhecem representações como formas interpretáveis. Nesse sentido, a textualidade (as padronizações descritas segundo os conceitos de coesão e de coerência) de um encadeamento significativo (formas de expressão) é o resultado de processos (opções) e de operações (de identificação, de diferenciação, de quantificação, de qualificação, de tipificação etc.) da atividade de linguagem no domínio cognitivo.

\section{A PRODUÇÃO E O RECONHECIMENTO DO MATERIAL SIMBÓLICO}

O linguista não tem acesso direto ao domínio cognitivo. No entanto, tem acesso indireto a esse domínio mediado pelo produto das operações cognitivas, a saber, as formas de expressão produzidas pelos sujeitos, seja em língua natural, seja em outros meios expressivos. Estamos nos pautando em nossa experiência de reflexão com a Teoria das Operações Enunciativas para teorizar a natureza do sistema cognitivo na produção e no reconhecimento de formas de expressão. Estamos empenhados em partir dessa reflexão para dialogar com domínios com os quais temos menos experiência de reflexão que são meios expressivos outros para além das línguas naturais.

A teoria de operações que praticamos não se ocupa de operações mentais per se independentemente dos traços dessas operações na diversidade das línguas e de meios expressivos ${ }^{2}$. Enquanto produto de operações cognitivas, as línguas naturais, assim como outros meios expressivos constituem traços dessas operações. Ao possibilitar o acesso ao nível cognitivo, esses traços permitem simular os 
processos que the deram origem e, com isso, explicam a função reguladora do sistema cognitivo na atividade de linguagem. Estamos, agora, em face do diálogo como questão teórica.

\section{O DIÁLOGO}

O diálogo ou função reguladora coloca em jogo um conjunto de relações de alteridade entre representações - linguísticas, musicais, imagéticas, gestuais, sonoras e cognitivas - de um sujeito e aquelas que ele acredita serem as representações de outro sujeito quanto ao universo psico-físico-cultural.

O conceito de diálogo de que tratamos aqui é um todo que compreende: o diálogo interior ou intrasubjetivo, que é anterior à situação de exteriorização do produto da atividade cognitiva e contemporâneo a ela, quer dizer, é o mesmo que traz consigo o outro-o mesmo; o diálogo exterior ou intersubjetivo, que é contemporâneo à situação de exteriorização do produto da atividade cognitiva e projetivo em relação a ela, quer dizer, é o outro que traz consigo o mesmo e o outrooutro; e uma forma de teleonomia, que é um processo que orienta as relações entre a anterioridade (o mesmo e o outro-o mesmo), a contemporaneidade (o outro-outro) e a projeção (o mesmo, o outro-o mesmo, o outro-outro), quer dizer, o diálogo entre o mesmo, o outro e a projeção emergente seja do mesmo, seja do outro-o mesmo e seja do outro-outro.

Destarte, a incursão pelas partes constituintes do diálogo dá-nos a exata dimensão do seu funcionamento na atividade de construção das formas de expressão. É preciso entender que o diálogo não existe sem as partes que o compõem e, ao mesmo tempo, nenhuma parte pode ser tomada como sendo o todo. É no movimento do todo em direção às partes e das partes em direção ao todo, ou seja, no processo de regulação que o diálogo acontece. O diálogo é o movimento de um ponto de estabilidade $P_{0}$, dado pelo mesmo e pelo outro-o mesmo, a outro ponto de estabilidade $P_{1}$ enunciado, dado pela adequação ao mesmo e ao outro-o mesmo ou pela emergência do outro-outro ${ }^{3}$. Na Figura 1 , o segmento entre $P_{0}$ e $P_{1}$ corresponde à instabilidade, ao diferente (outro-outro). 
Figura 1 - Representação do movimento de um ponto de estabilidade (o igual) que passa pela instabilidade (pela possibilidade do diferente) e se estabiliza novamente em outro ponto mais complexo.

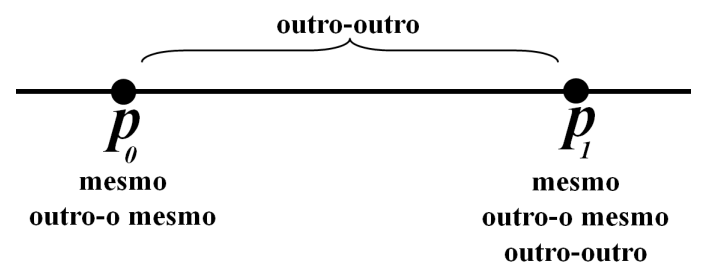

Do ponto de vista cognitivo, o diálogo é um programa de adaptação e de equilibração evolutiva que orienta tanto a exigência de adequação ao mesmo (igual) quanto a emergência do outro (diferente) que podem se realizar em $P_{1}$. Na atividade de linguagem, o diálogo regula operações de determinação (em direção ao mesmo) e de indeterminação (em direção ao diferente) constitutivas da produção e do reconhecimento de enunciados. Essa dinâmica levou Antoine Culioli, linguística francês que delimitou as bases do programa teórico pelo qual nos orientamos neste capítulo, a definir o diálogo como "atividade metalinguística não consciente do sujeito" (CULIOLI, 1990, p. 26) ${ }^{4}$. Essa definição está calcada na capacidade de ajustamentos dos sujeitos quanto a quadros de referência e de representação e na reflexão inconsciente dos sujeitos sobre sua própria atividade de linguagem, cujas marcas das operações subjacentes estão presentes nos enunciados, conforme veremos na seção 4 deste artigo.

Em consonância com esse referencial, assumimos a hipótese de que todo produto da atividade de linguagem está inserido em um diálogo, o que implica supor a contradição no empírico. Se considerarmos uma configuração dada em $P_{1}$, teremos de considerar que, para chegar a esse ponto, esteve antes em $P_{0}$, saiu desse ponto e percorreu o intervalo que se encontra entre esses dois pontos. Embora estabilizado em $P_{1}$, todo configuração de uma forma de expressão traz as marcas da tensão colocada pelo deslocamento entre os dois pontos. Há diálogo entre o empírico (que se coloca diante do sujeito como universo de experiência) e o cognitivo (estados de conhecimento relativamente estáveis), resultando desse diálogo a estabilização do cognitivo (o sujeito, o mesmo) em um ponto superior e mais complexo, devido ao percurso percorrido entre $P_{0}$ e $P_{1}$.

Existem objetos no mundo com os quais entramos em contato todos os dias desde a infância. A manipulação das diferentes constituições desses objetos e a 
observação de sua participação em eventos variados é fonte de processos cognitivos de categorização e de construção de representações no interior da cultura. A partir da interação do sujeito com o mundo ${ }^{5}$, a cognição estrutura sistemas complexos de propriedades físico-culturais que denominaremos noções e que se estruturam em domínios de referência que denominaremos domínios nocionais.

\section{A NOÇÃO E O DOMÍNIO NOCIONAL}

O reconhecimento de uma noção é resultado de um procedimento metodológico que opera a passagem de uma ocorrência fenomenológica a uma ocorrência abstrata. Essa tarefa envolve: distinguir ocorrências fenomenológicas, identificar propriedades, estimar a distância uma da outra, medir o grau e o tipo de similaridade e decidir entre manter as ocorrências qualitativamente distintas ou categorizá-las como identificadas com relação a uma tipificação.

Essa tipificação às vezes se confunde com estereótipos e até mesmo com preconceitos, porque faz intervir o estável - dado pela representação de propriedades físico-culturais definidas no interior de uma cultura e socializadas entre os sujeitos nela inseridos - e a ela se opõe o deformável - dado pelas modulações do sujeito sobre o estável (ou o que é tido como estável nas relações intersubjetivas) segundo sua vontade, desejo e intenção. O sujeito está, assim, na origem e no movimento das representações que constrói.

Estamos diante do desafio de trabalhar sobre domínios híbridos de articulação que relacionam aquilo que foge à nossa alçada de linguistas, tais como os processos cognitivos de categorização e de construção de representações ${ }^{6}$, com aquilo que nos é próprio, a saber, as representações linguísticas (arranjos léxicogramaticais das línguas naturais) como produto da atividade de linguagem.

Se, por um lado, as noções podem ser abordadas como entidades cognitivas apreciadas por uma dada cultura, o que extrapola os domínios do linguista, por outro lado, também podem ser abordadas como manifestações enunciativas de uma dada língua e, nesse caso, só podem ser apreendidas através de ocorrências materiais inscritas em um sistema de referencia definido pelos parâmetros sujeito e tempoespaço no qual uma forma de expressão se configura.

Para tanto, é preciso reconhecer que esses eventos operam um recorte sobre a noção. De um lado, o recorte é quantitativo (QNT) e, de outro lado, qualitativo 
(QLT). Primeiro é construída a ancoragem situacional da ocorrência e há, portanto, traço da sua manifestação, da sua existência (real ou imaginária); segundo, é construída sua estruturação subjetiva, que consiste na avaliação de uma ocorrência em relação a um protótipo (o estável), para que tipos de ocorrência sejam eventualmente distinguidos. Uma ocorrência de um tipo distingue-se de outra ocorrência de tipo diferente.

Uma segunda dimensão qualitativa também será pertinente na construção de uma ocorrência. Essa dimensão, ao invés de distinguir um tipo de ocorrência de uma ocorrência de outro tipo, distingue uma ocorrência de certo tipo de uma ocorrência do mesmo tipo. Assim, se a primeira dimensão qualitativa é característica da identificação de ocorrência, já que é "por identificação, [que] o sujeito estabelece que uma ocorrência $\boldsymbol{\alpha}$ é uma ocorrência da noção $\boldsymbol{A}$ " (CULIOLI, 1990, p. 96), a segunda dimensão coloca em questão a diferenciação de ocorrências possíveis e imagináveis umas em relação às outras, no interior do domínio nocional.

A função desse domínio é estruturar classes de ocorrências da noção em um espaço topológico composto por um interior ("o verdadeiramente p"), por um exterior ("o verdadeiramente não-p") e por uma fronteira (" $p$ até determinada extensão" e "não-p até determinada extensão"). A Figura 2 representa esquematicamente esse espaço topológico.

Figura 2 - Esquematização do conceito de domínio nocional adaptada de

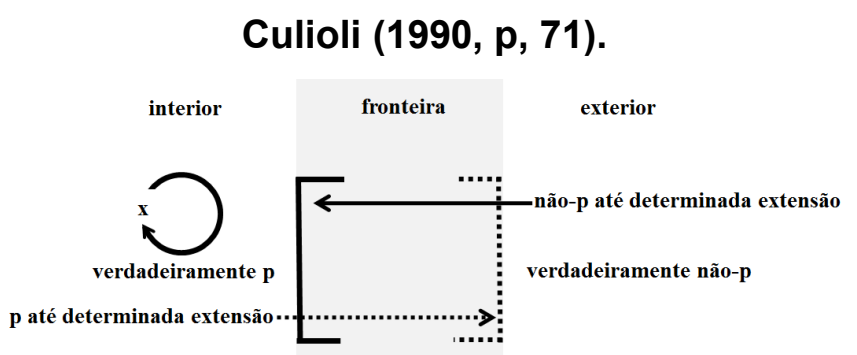

O interior do domínio é um espaço aberto orientado por um processo de identificação ( $u m X_{i}$ é identificado com um $X_{j}$ ) de maneira que não há um ponto inicial ou final que o delimite. Isso é possível porque no interior há um centro organizador (protótipo) que organiza todo o domínio. Os valores para o interior podem ser informalmente glosados como "verdadeiramente $p$ ", "verdadeiramente representativo de $p$ ". O exterior resulta de um processo de diferenciação que pressupõe uma identificação anterior. Os valores exteriores ao domínio podem ser 
descritos como "verdadeiramente não-p", "totalmente diferente de p", "não tendo nenhuma propriedade em comum, nem a mais tênue, com $p "$.

Recorremos à área de fronteira para discernir ocorrências não homogêneas, tais como $X_{m}$ e $X_{n}$, de uma noção $p$, que evidenciam estados qualitativamente alterados da propriedade $p$. Fechando o interior do domínio, organizamos ocorrências em contínuo sobre não- $p$, mas ainda pertencentes à área- $p$. Os valores para esse fechamento do interior podem ser glosados como " $p$ até certa extensão, qualquer que seja, uma vez que se mantém sobre o lado de p" ou "não verdadeiramente $p$ ". Fechando o exterior, organizamos valores que podem ser glosados como "não-p até certa extensão, qualquer que seja, uma vez que nos mantemos sobre o lado de não-p" ou "não verdadeiramente não-p". Há, portanto, uma complementaridade entre o interior e o exterior do domínio na definição de valores das ocorrências da noção.

O domínio nocional compreende um domínio abstrato, não de representações cognitivas, mas de representações metalinguísticas que estruturam ocorrências da noção. O trabalho com essas representações dentro de um programa teórico tem por finalidade estabelecer correspondências entre operações do nível cognitivo com marcadores dessas operações em meios expressivos particulares, dentre eles as línguas naturais.

\section{O COLOCAR EM FORMA DA NOÇÃO E A CONSTRUÇÃO DA SIGNIFICAÇÃO}

Assumindo esse objetivo de mostrar como se constroem as categorias (texto, multitexto, substantivo, adjetivo etc.), estudamos a significação não do ponto de vista da classificação da superfície das formas de expressão ou dos meios expressivos, mas do ponto de vista de um conjunto de operações elementares tais como a quantificação, a qualificação, a extração e a identificação/diferenciação.

Essas operações são responsáveis pelo processo de constituição de um objeto (a forma da expressão), isto é, pela maneira como uma forma de expressão se coloca em forma. Esse colocar em forma é produto do quê? Esse colocar em forma é parte de um processo mais amplo que aciona um conjunto de parâmetros abstratos internos à atividade de linguagem (VOGÜÉ, 1992). Nesse caso, a forma de expressão será entendida como o agenciamento de vestígios das operações 
realizadas na sua construção como resultado da atividade de linguagem dos sujeitos sobre o empírico.

O objeto de análise se configura agora como a maneira pela qual a forma de expressão tem a forma que tem, quer dizer, o objeto da linguística está entre o empírico (diversidade experiencial e de formas de expressão dos diversos meios expressivos) e o formal (a atividade de linguagem), e não no empírico (Estruturalismo) ou no formal (Racionalismo).

Esse caminho teórico determina para as formas de expressão um duplo estatuto - teórico e material. São unidades empíricas de observação porquanto constituídas de materialidade e, por isso, o dado mais diretamente observável à análise; são entidades teóricas porquanto são definidas como agenciamento de marcadores de operações da atividade de linguagem. Dessa perspectiva, partiremos de dados imediatos e caminharemos em direção à formulação de dados teorizados que nos fornecem subsídios para retornar ao empírico e, nesse movimento, sustentados pela articulação da linguagem com a diversidade dos meios expressivos, apresentaremos explicações plausíveis sobre as condições de produção e de reconhecimento das formas de expressão de partida ${ }^{7}$ com base em representações metalinguísticas explicitadas pelo modelo teórico.

$\mathrm{Na}$ sequência, oferecemos ao leitor a análise de uma configuração particular em língua natural. Trata-se de um enunciado extraído do jornal Folha de São Paulo em sua versão eletrônica. As manipulações que fazemos nesse movimento de análise têm por objetivo explicitar como se estrutura o domínio nocional da noção /ser médico/ e como o adjetivo "falso" participa dos processos constitutivos do enunciado.

\section{A NOÇÃO /SER MÉDICO/ E O ADJETIVO "FALSO"}

Nos trabalhos que se dedicam ao estudo do adjetivo, é fulcral a definição de valores que sejam próprios à categoria. Há um número razoável de trabalhos produzidos por lógicos e linguistas no intuito de definir esses valores.

Os lógicos, diante do compromisso de referenciar as expressões linguísticas, seja em um mundo sensível seja em um mundo intelectivo, conseguiram atribuir à categoria tanto um valor intensional (MONTAGUE, 1970; PARSONS, 1968) quanto um extensional (KAMP, 1975). Uma versão dessa abordagem lógica em língua 
portuguesa encontra-se em Borges Neto (1991). Os linguistas, sem o compromisso de referenciar as expressões linguísticas em um mundo outro que não seja aquele idealizado pelo conceito de langue, sentem-se na liberdade de atribuir à categoria e às subcategorias tantos valores quanto sua imaginação Ihes permite fazer. Esse procedimento está respaldado por um paradigma teórico que opera com o conceito de média experiencial (signo) implícito à. Para tanto, assumem que quaisquer linguistas em iguais condições (no mesmo universo físico-cultural) atribuirão os mesmos valores às unidades. O que temos observado ao longo de quase dez anos de dedicação à questão do adjetivo é que a proliferação na definição de valores presentes na literatura sobre o tema é bastante. Onde a metodologia se esgota, a experiência subjetiva se impõe como expediente metodológico que sustenta a análise e seus resultados e, pior, sem a devida explicitação das opções que foram feitas durante o percurso que resultou na definição de valor(es) próprio(s) à categoria. Dados os propósitos deste artigo, não incursionaremos por esses valores aqui.

Partindo da articulação da linguagem com as línguas naturais, assumimos que a comunicação linguística compreende um espaço referencial que é a base comum compartilhada por interlocutores. Esse espaço caminha de um vazio referencial em direção a um espaço referencial consideravelmente especificado na medida em que os interlocutores regulam seus quadros de referência em relação a essa situação particular de interlocução. Ademais, assumimos que o significado é algo que se movimenta. Qualquer tentativa de descrevê-lo será reducionista, pontual e circunstancializada. O que temos de material são as formas interpretáveis (os enunciados). O significado das formas de expressão não é estável porque está inserido em um contínuo e sua espessura é diametralmente dependente do universo experiencial de cada sujeito interpretante. Assim, o que denominamos significado corresponde a algum ponto que se cristaliza em função da sua focalização devido a um procedimento analítico.

O enunciado de que partimos é um dentre muitos outros que foram descartados no processo que o gerou. Fizemos o esforço de tentar reconstruir o processo da sua constituição desde a sua gênese. Para nós, a beleza foi observar que o adjetivo "falso" é marca do diálogo intra e intersubjetivo. Partimos do seguinte enunciado: A Polícia Civil gaúcha procura desde esta quinta-feira um falso médico acusado de ter exercido ilegalmente a profissão por ao menos dois anos em São 
Sebastião do Caí (região metropolitana de Porto Alegre). Ele chegou a atuar como diretor geral de um hospital filantrópico.

O sujeito extrai uma ocorrência da noção /ser médico/. Essa operação pode ser glosada pelo enunciado:

A polícia procura um médico (dentre outros).

Essa extração consiste na individuação de uma ocorrência da noção /ser médico/. Isso requer que a ocorrência seja localizada em relação a um sistema situacional. Para atribuir um estatuto existencial à ocorrência, o sujeito enunciador se depara com uma tensão quanto à existência da representação. Assim glosamos essa tensão:

A polícia procura alguma coisa que existe, e por isso deve continuar procurando, em algum momento encontrará alguma coisa que está procurando.

A polícia procura alguma coisa que não existe, e por isso não precisa mais procurar, pode parar de procurar, porque não há alguma coisa a ser procurada.

O sujeito observa o empírico e, ao enunciar, estabiliza o enunciado favorável à existência da representação. "Procura" representa, ao mesmo tempo, um /fazer/ da Polícia Civil gaúcha e a modalidade do possível e do provável, portanto, favorável à existência de alguma coisa.

Até aqui, abstraímos do caráter qualitativo da noção em função da sua delimitação quantitativa (sua delimitação espaço-temporal no processo enunciativo), cuja existência o enunciado traz marcas que a confirmam de modo que se possa referi-la para, posteriormente, localizar essa ocorrência em relação ao centro organizador de um agregado de ocorrências e definir seu modo de ser. É preciso que alguma coisa exista no pré-construto para que possa ser avaliada qualitativamente, através da operação de identificação/diferenciação, ampliando o domínio de compreensão de uma ocorrência. 
No caso em questão, para chegarmos ao modo de ser da noção /ser médico/, consideraremos que:

Será $X$ aquele que tiver a propriedade $P$.

Será médico aquele que tiver a propriedade /ser médico/.

Quem responde à pergunta "A ocorrência em questão tem a propriedade /ser médico/?" é o próprio enunciado. Para responder a essa pergunta, o enunciador se baseia no diálogo entre dois sujeitos $S_{1}$ e $S_{2}$ no pré-construto. Primeiro, esse diálogo se centra na existência da relação $/ S_{1}$ ter exercido a medicina/ no tempo $T_{0}$ anterior ao do enunciado. Vejam-se as glosas desse pré-construto:

$S_{1}$ ter exercido a medicina houve/existiu

$S_{1}$ ter exercido a medicina não houve/ não existiu

$S_{2}$ valida a relação no pré-construto. É com base nessa validação que $S_{2}$ acusa $S_{1}$. Glosamos essa validação do seguinte modo:

A medicina exercida por $S_{1}$ não agradou $S_{2}$ que, por isso, fez alguma coisa em prejuízo de $S_{1}, S_{2}$ acusou $S_{1}$ por aquilo que $S_{1}$ fez.

O enunciador, diante disso, ao retomar esse pré-construto, no enunciado, emprega o particípio do verbo "acusar" para representar não só um fazer de $\mathrm{S}_{2}$ cujo resultado (desfavorável) recai sobre $S_{1}$, mas também um valor modal favorável à existência da relação no pré-construto, confirmando a validação da relação feita por $\mathrm{S}_{2}$ no pré-construto.

Nesse caso, como houve uma ocorrência de $/ S_{1}$ ter exercido a medicinal, $S_{1}$ é médico. Temos, portanto, a identificação qualitativa da noção com o centro organizador do domínio. Glosamos essa ocorrência:

A Polícia Civil gaúcha procura desde quinta-feira um médico que tem exercido a profissão por ao menos dois anos em São Sebastião do Caí. Uma presidiária o aguarda para ser atendida no hospital penitenciário da cidade. 
$O$ sujeito $S_{0}$ do enunciado que estamos analisando dialoga ainda com outro diálogo entre $S_{1}$ e $S_{2}$ no pré-construto. Se, por um lado, o sujeito $S_{2}$ valida a relação $/ S_{1}$ ter exercido a medicina/ em um tempo inicial $T_{0}$, por outro lado, $S_{2}$ não a valida em um tempo $T_{1}$ posterior a $T_{0}$. Estamos, agora, caminhando para o exterior do domínio nocional, onde não há identificação qualitativa da noção /ser médico/ com o interior do domínio. Veja-se a glosa dessa ocorrência:

A medicina exercida por $S_{1}$ não existiu. Alguma coisa que $S_{1}$ fez foi qualquer coisa menos a medicina exercida por $S_{1}$.

Concluímos que, por um lado, $S_{2}$ valida a relação em $T_{0}$ para que possa, com isso, usar algo que $S_{1}$ fez em prejuízo de $S_{1}$ e, por outro lado, o mesmo $S_{2}$ não valida a relação no tempo $T_{1}$, posterior a $T_{0}$, para se colocar como obstáculo a que $\mathrm{S}_{1}$ seja médico em $\mathrm{T}_{1}$.

Comparando os diálogos dos sujeitos $S_{1}$ e $S_{2}$ nos tempos $T_{0}$ e $T_{1}$ do préconstruto, o sujeito enunciador $S_{0}$ observa a contradição instaurada por $S_{2}$ que valida e não valida uma mesma relação em tempos sucessivos. No tempo $T_{2}$, que é o tempo do enunciado, $\mathrm{S}_{0}$ marca essa contradição com o adjetivo "falso" e estabiliza o enunciado com a modalidade intersubjetiva "ilegalmente" favorável à não-validação da relação, em consonância com o posicionamento de $S_{2}$ em $T_{1}$.

\section{CONCLUSÃO}

A reflexão que desenvolvemos neste artigo nos conduziu a algumas questões que nos são pertinentes há algum tempo sobre a especificidade linguística e a sua articulação com a atividade de linguagem e outros meios expressivos que, assim como as línguas naturais são resultado do trabalho dos sujeitos sobre o empírico.

Concluímos o artigo com uma trajetória de análise que partiu de um ponto de estabilidade (nosso enunciado de partida) e passou pela instabilidade até chegar à estabilização novamente de valores que aquela configuração (forma de expressão) particular traz na sua constituição. 


\section{NOTAS}

${ }^{1}$ Licenciado e Bacharel em Letras. Mestre e Doutor em Linguística e Língua Portuguesa. Professor do Programa de Pós-Graduação em Linguística da UNEMAT, em Cáceres (MT), e do Curso de Letras da UNEMAT, em Alto Araguaia (MT).

${ }^{2}$ A atividade cognitiva transcende o domínio da linguística porque lida com problemas tais como percepção, gosto, antipatia, representações coletivas e propriedades subjetivas e culturais de objetos para os quais a linguística não dispõe de recursos analíticos adequados e satisfatórios.

${ }^{3} \mathrm{O}$ movimento que leva a $P_{1}$, além do enunciado estabilizado, terá gerado muitos outros que permanecem no depósito dos recalques do inconsciente sem sequer ter alçado ao patamar da consciência.

${ }^{4}$ Culioli (1999a, p. 74) também emprega o termo "épi-linguistique", do francês, para referir essa atividade.

${ }^{5}$ São comuns separações entre mundo exterior, "objetivo", e interior, "subjetivo". Tal separação não se sustenta quando consideramos que são os sujeitos, na sua interioridade, na sua subjetividade, a origem dessa oposição. Compartilhamos das colocações de Rezende (2000, p. 180) quando afirma que "a realidade subjetiva (mental ou emocional) ou objetiva (mundo físico-cultural) tornam-se sempre subjetivas enquanto realidades percebidas" pelos sujeitos.

${ }^{6}$ Esses domínios, embora não sejam da alçada do linguista, a ele se impõem para que seja estabelecido o diálogo entre domínios conexos de conhecimentos.

${ }^{7}$ Esse movimento foi denominado por Culioli (1990, p. 21-22) como "teoria dos observáveis".

\section{REFERÊNCIAS}

BORGES NETO, J. Adjetivos: predicados extensionais e predicados intensionais. Campinas: Unicamp, 1991.

CULIOLI, A. Linguistique du discours e et discours sur la linguistique. Revue philosophique, n. 4, p. 481-488, 1978.

. Pour une linguistique de l'énonciation: formalisation et opérations de repérage. Paris: Ophrys, 1999. v. 2.

. Pour une linguistique de l'énonciation: opérations et représentations. Paris: Ophrys, 1990. v. 1.

CUMPRI, M. L. Reflexões sobre a produção e o ensino do texto por meio de uma perspectiva enunciativa. Uniletras, v. 31, n. 2, p. 27-36, 2009.

KAMP, J. A. W. Two theories about adjectives. In: KEENAN, E. L. Formal semantics of natural language. Cambridge: Cambridge University Press, 1975.

MONTAGUE, R. English as a formal language. In: VISENTINI, B. et al. (Eds.) Linguaggi nella società e nella tecnica. Milan: Edizioni di Comunità, 1970, p.189-224. 
PARSONS, T. A semantics for English. [s.I.], 1968.

REZENDE, L. M. Léxico e gramática: aproximação de problemas linguísticos com educacionais. Tese (Livre docência) - Faculdade de Ciências e Letras da Universidade Estadual Paulista, Araraquara, 2000.

VOGÜÉ, S De. Culioli après Benveniste: énonciation, langage, intégration. Linx, n. 26, p. 77-108, 1992. 